\section{New law threatens to undermine genetics in New Zealand}

\section{Peter Pockley}

Researchers and government officials in New Zealand are pinning their hopes on a royal commission to end their struggle over a strict law governing use of genetically modified organisms (GMOs) in research (see Nature 404, 914; 2000).

But the Royal Commission on Genetic Modification might not report for up to two years. During that time, says Clive Ronson, the biological safety officer at the University of Otago, "New Zealand scientists have to face retrograde legislation that is based on organisms rather than projects and undermines our competitiveness".

Last April, government officials suspended the authority of all institutions' internal committees to license GM research. The move followed investigations by the Environmental Risk Management Authority (ERMA) of experiments that had not been approved under the Hazardous Substances and New Organisms (HSNO) Act.

Researchers are now protesting at the fact that ERMA classes every modification to an organism, however minor, as a new organism, requiring a lengthy and costly application for approval (see page 13). As a result, hundreds of projects have been placed on hold, awaiting approval.

Although few have made public statements, biochemist Jon Hickford of Lincoln University near Christchurch recently told the city's daily newspaper, The Press, that ERMA had failed to explain to the public the "low risk" posed by routine modification of plasmids in bacterial strains. He said ERMA should concentrate on the larger challenges posed to the biosecurity of New Zealand's agricultural economy by animals and insects entering the country.

Bas Walker, ERMA's chief executive, responded by accusing Hickford of "trying to shoot the messenger because the message is unpalatable".

Last week, the University of Auckland announced that it would have to devote up to NZ\$1 million (US\$468,000) of its NZ\$15 million GMO-research funding to meeting what it calls "inappropriate requirements" imposed by the HSNO Act.

Walker revealed that, after a nationwide check by ERMA following the first breach, 27 facilities throughout New Zealand had reported 1,065 GM experiments, of which 152 had not received approval.

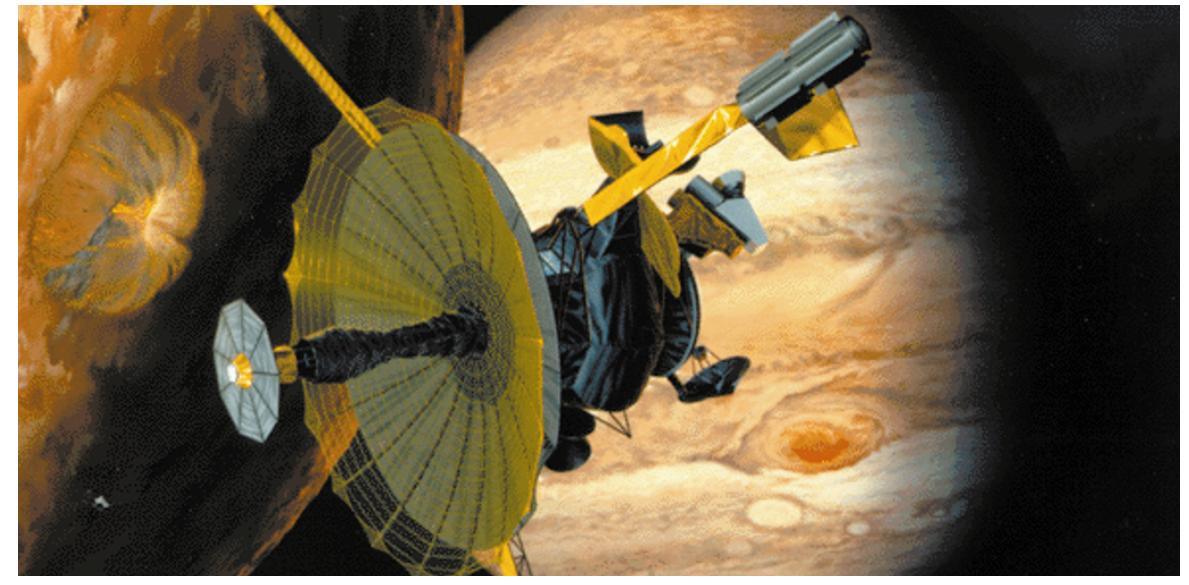

Life saver? The spacecraft Galileo will plunge into Jupiter's atmosphere to protect Europa (left).

\title{
Galileo set for suicide flight
}

Heather McCabe

A US National Academy of Sciences panel last week endorsed plans to send NASA's Galileo spacecraft on a suicide mission into Jupiter's atmosphere. The move is a bid to avoid contaminating the planet's potentially lifeharbouring moons, in particular Europa.

At the same time, the Committee on Planetary and Lunar Exploration, part of the academy's Space Studies Board, agreed to get as much science as possible out of the spacecraft before its navigation systems fail. Galileo was originally launched in 1989 and has been orbiting Jupiter since 1995.

The spacecraft is scheduled to complete a series of fly-bys of Io, one of Jupiter's moons, delaying the craft's destruction by a year. But this is not thought likely to increase the chance of an accidental crash into Europa. Some believe that this moon has a liquid ocean under its ice crust that could contain simple life-forms. Any terrestrial organisms still alive on Galileo could potentially contaminate the moon.

"The probability of total loss of control during this extra year is relatively small," concludes the report. "Moreover, the chances of total failure can be mitigated by prudent monitoring of the spacecraft's health and by a commitment on the part of NASA to retarget Galileo onto a Jupiterbound trajectory following the loss of redundancy in any major command and control subsystem."

\section{Astronomers fight to save telescope}

\section{Rex Dalton, San Diego}

Astronomers are fighting to save the 12Meter Telescope at Arizona's Kitt Peak from closure at the end of July. The National Radio Astronomy Observatory hopes to save about $\$ 2$ million by mothballing the telescope - the only millimetre-wavelength facility available to all US astronomers.

The observatory operates the telescope for a consortium of universities (see Nature 404, 7; 2000). But the University of Arizona in Tucson and the University of Massachusetts at Amherst joined forces with dozens of astronomers late last month to develop a proposal to keep it operational.

Millimetre-wavelength telescopes are used to examine the early phases of star formations in supercold molecular clouds. For instance, researchers using the 12-Meter Telescope recently discovered deuterium (a form of hydrogen) in the Milky Way (Ludowich, D. A. et al. Nature 405, 1025-1027; 2000).
Astronomers from Arizona and Massachusetts met last week with the National Science Foundation (NSF), which owns the facility. "The astronomy community is working very diligently to come up with a solution," says James Breckinridge, an NSF astronomy programme manager.

Later this month, the universities plan to submit an interim proposal to the NSF to operate the telescope with the agency. To begin operations on 1 August, the two universities have secured a \$150,000 donation from Research Corp., a Tucson-based nonprofit-making corporation.

The NSF will decide later this month what will happen on 31 July when the telescope is due to shut down. The astronomers are also writing a three-year research plan, to be sent to the NSF later this year.

A joint US-Mexican project is under way to build a millimetre-wavelength telescope with a 50-metre dish in Mexico. But this will not come into operation until 2003. 